\title{
A comparison between induction of labor with 3 methods of titrated oral misoprostol, constant dose of oral misoprostol and Foley catheter with extra amniotic saline infusion (EASI), in women with unfavorable cervix
}

\author{
Maryam Kashanian*1, 2 , Shohreh Bahasadri ${ }^{1}$, Ashraf Nejat Dehkordy ${ }^{1}$, Narges Sheikhansari ${ }^{3}$, Noushin Eshraghi ${ }^{1,2}$
}

Received: 11 Jun 2018

Published: 28 Oct 2019

\begin{abstract}
Background: Different methods of cervical ripening and induction of labor have been used in the cases of unfavorable cervix with different levels of success, but no method has been found to be the best option. The purpose of the present study was to find the effects and side effects of three different methods of cervical ripening and induction of labor. These three methods were oral titrated misoprostol, constant dose of oral misoprostol and Foley catheter with extra-amniotic saline infusion.

Methods: This clinical trial was performed on women with unfavorable cervix who had been admitted in Akbarabadi Teaching Hospital for induction of labor and had bishop score of less than six; between March 2014- March 2015. The eligible women were assigned into three groups. In titrated oral misoprostol group $(n=33)$, titrated solution of misoprostol, and in oral misoprostol group $(n=33)$, 50 $\mu$ g oral misoprostol every four hours and in Foley catheter group $(\mathrm{n}=50)$, Foley catheter with extra-amniotic saline infusion were administered. The main outcome was the number of vaginal deliveries during the first 24 hours. In addition, number of cesarean deliveries and adverse effects were compared between the three groups. The obtained data were analyzed using SPSS 18 software. Data analysis was performed according to the intention to treat principle. Chi-square test, Fisher Exact test, Student ttest, and Mann-Whitney U test, were used for comparing data. P-value $\leq 0.05$ was considered statistically significant.

Results: The three groups did not have any significant difference according to maternal age, gestational age at the time of admission, gravidity, parity, and primary Bishop Score. There was no significant difference between the three groups for the main outcome, which was vaginal delivery during the first 24 hours $(\mathrm{p}=0.887)$. There was no significant difference between the three groups according to hypertonicity, uterine hyperstimulation, meconium passage, non-reassuring fetal heart rate, neonatal Apgar score in minutes one and 5, and mean duration of beginning the intervention up to delivery. However, uterine tachysystole and NICU admission were more in the group to whom the titrated solution of misoprostol was administered ( $\mathrm{p}=0.002$ and $\mathrm{p}=0.037$ respectively). The number of cesarean deliveries due to failure to progress was higher in the EASI group. However, EASI group showed the least number of none-reassuring fetal heart rate between the three groups. Meconium passage was more in the titrated misoprostol group, but the difference was not significant.

Conclusion: All three methods are appropriate methods for induction of labor in the cases of unfavorable cervix; and choosing each method depends on the expertise of labor staff, accessibility to the medications, cost, and taking care for monitoring the patients and adverse effects.
\end{abstract}

Keywords: Cervical ripening; extra-amniotic saline infusion (EASI), Foley catheter, Induction of labor, Misoprostol, Prostaglandin E1, Meconium, Tachysystol

Conflicts of Interest: None declared

Funding: None

*This work has been published under CC BY-NC 4.0 license.

Copyright $@$ Iran University of Medical Sciences

Cite this article as: Kashanian M, Bahasadri Sh, Nejat Dehkordy A, Sheikhansari N, Eshraghi N. A comparison between induction of labor with 3 methods of titrated oral misoprostol, constant dose of oral misoprostol and Foley catheter with extra amniotic saline infusion (EASI), in women with unfavorable cervix. Med J Islam Repub Iran. 2019 (28 Oct);33:115. https://doi.org/10.47176/mjiri.33.115

Corresponding author: Dr Maryam Kashanian, maryamka@iums.ac.ir

1. Department of Obstetrics \& Gynecology, Iran University of Medical Sciences, Akbarabadi Teaching Hospital, Tehran, Iran

2. National Association of Iranian Obstetricians \& Gynecologists (NAIGO), Tehran, Iran

3. Faculty of Medicine, University of Exeter, Exeter, UK $\uparrow$ What is "already known" in this topic:

Different methods of cervical ripening and induction of labor have been used in the cases of unfavorable cervix with different levels of success, but no method has been found to be the best option.

$\rightarrow$ What this article adds:

All three methods are appropriate methods for induction of labor in the cases of unfavorable cervix; and choosing each method depends on the expertise of labor staff, accessibility to the medications, cost, and taking care for monitoring the patients and adverse effects. 


\section{Introduction}

More than 20 percent of pregnant women need induction of labor (1), which can be performed with different methods. Oxytocin is the most common medication that is used for this purpose (2). However, in the cases with unfavorable cervix; there are various methods of cervical ripening which will be used before starting the labor induction process. Mechanical methods were the oldest methods used for cervical ripening (3), which have been substituted by pharmaceutical agents in recent years. However, mechanical methods are simpler, safer, and cheaper, with less adverse effects, and they do not need any specific temperature preservation (3).

Among various pharmaceutical methods, a commonly studied medication which has regularly been introduced as the best option for cervical ripening is misoprostol (Cytotec Searle), which is a prostaglandin $\mathrm{E}_{1}$ analogue (4-10), and it is used off-label for induction of abortion and labor. Misoprostol can be used in different ways, including oral, vaginal, sublingual, buccal, titrated solution and rectal (4-11). Prostaglandin $\mathrm{E}_{2}(12-16)$, prostaglandin $\mathrm{F}_{2} \alpha$ (12), mifepristone (17), nitric oxide donors $(18,19)$, corticosteroids (2022), propranolol (23), estrogen (24), hyaluronidase (25), and relaxin (26) are among the pharmaceutical agents which have been used for cervical ripening and induction of labor.

Mechanical methods which have been used for this purpose, include balloon catheter with and without traction on the cervix $(5,21,27)$, with different capacities for the bulb of foley catheter (28), and with adding extra-amniotic saline infusion $(3,21,27)$. The other mechanical methods are intracervical dilators, including both natural (laminaria) and synthetic (Dilapan) (3). Sweeping of the membranes (29), breast stimulation (30), sexual intercourse $(31,32)$, using castor oil, bath and/ or enema (33), traditional methods like acupressure and acupuncture (34), are amongst the methods used for cervical ripening and labor induction assistance which all have some levels of success rate. There are many studies, which compare these different methods with each other, with different results. It would be beneficial for further studies to be performed in order to compare these methods to reach a definitive conclusion and finding the best method.

The purpose of the present study was to compare mechanical methods of extra amniotic saline infusion, and misoprostol with two different forms (oral misoprostol and titrated solution of misoprostol) for induction of labor in the cases of unfavorable cervix with low bishop score.

\section{Methods}

The study was performed as a non-randomized prospective clinical trial on pregnant women who were admitted to the labor ward of Akbarabadi Teaching Hospital for induction of labor and had bishop score of less than six; between March 2014- March 2015. Written informed consent was obtained from all participants. They were fully informed about the study, and institutional review board approval and also institutional ethics committee approval was given to the study which was also registered in Iran
Registry of Clinical Trial (IRCT).(Trial registration number IRCT201702282624N22).

Inclusion criteria included maternal age between 18-40 years old; gestational age of more than 37 weeks (according to certain LMP and ultrasound confirmation of the first trimester of pregnancy); singleton; cephalic presentation; intact membrane and Bishop Score of less than 6. Exclusion criteria were any sign of fetal distress; placenta previa and any vaginal bleeding of more than bloody show; history of any surgery on uterus including cesarean section; and known uterine anomaly; intra-uterine fetal death; and known hypersensitivity to misoprostol. Firstly, all women were examined by an investigator for determination of Bishop Score and eligibility. Eligible women were assigned according to the choice of obstetrician into three groups.

In the oral misoprostol group, $50 \mu \mathrm{g}$ misoprostol was administered, and women were followed up to 4 hours. FHR and uterine contractions were checked hourly. In the cases of not having suitable contractions after 4 hours, another 50 $\mu \mathrm{g}$ of misoprostol was administered every 4 hours until obtaining suitable contractions or up to maximum 6 doses (300 $\mu \mathrm{g}$ totals). Then the women were followed up to delivery. Suitable contractions were defined as forceful contractions with duration of 40-50 seconds and intervals of 2 minutes.

In the group of titrated solution of misoprostol, $200 \mu \mathrm{g}$ misoprostol tablet was solved in $200 \mathrm{~mL}$ of water (this solution is stable in the room temperature and contains $1 \mu \mathrm{g}$ misoprostol in $1 \mathrm{~mL}$ of solution). First, $20 \mathrm{~mL}(20 \mu \mathrm{g})$ of misoprostol was administered hourly for 4 hours. Then in spite of not having suitable contractions, $40 \mathrm{~mL}(40 \mu \mathrm{g})$ of misoprostol solution was administered every 1 hour for 4 doses and was repeated after 4 hours with $60 \mathrm{~mL}(60 \mu \mathrm{g})$ of misoprostol solution for a maximum of 4 doses (in total $480 \mu \mathrm{g})$. With appropriate contractions, misoprostol was discontinued during the labor process. Whenever appropriate contractions were ceased, $10 \mathrm{~mL}$ of solution was prescribed and was increased to $20 \mathrm{~mL}$ one hour later in case of not having favorable contractions in the incremental manner of 10-20-30-up to $40 \mathrm{~mL}$ per hour.

In the EASI group, Foley catheter of number 18 was introduced through the cervical canal and was filled with 30 $\mathrm{mL}$ distilled water and was fixed above the internal cervical ostium, and was connected to normal saline solution. The normal saline was entered into the uterus with the rate of 30 drops per minute. After the expulsion of the Foley catheter, oxytocin was started in the amount of $2.5 \mathrm{mUI} / \mathrm{min}$ and was increased every 15 minutes up to $40 \mathrm{mUI} / \mathrm{min}$.

The main outcome was defined as the number of vaginal deliveries during the first 24 hours. In addition, number of cesarean deliveries and adverse effects were compared between the three groups. In all women careful monitoring of fetal heart rate (FHR) and maternal condition was performed.

Uterine tachysystole was defined as more than five contractions per 10 minute for at least two repeated ten-minute periods. Uterine hyperstimulation was defined as uterine 
tachysystole plus non-reassuring FHR. Uterine hypertonicity was defined as contractions with a duration of more than 2 minutes plus non-reassuring FHR. FHR and uterine contractions were checked every 1 hour in the latent phase of labor and every 30 minutes in the active phase of labor. Blood pressure and pulse rate were monitored every 2 hours.

In both misoprostol groups, in the case of not having delivery during the first 24 hours, oxytocin was started 4 hours after the last administered misoprostol. To obtain a power of $80 \% \quad(\alpha=0.05)$, we planned to include 30 participants in each group as we assumed that it would be possible to detect a difference of 10 percentage points in the main outcome (according to previously published data) between the three groups. Sampling was performed as consecutive sampling. The obtained data were analyzed using SPSS 18 software. Data analysis was performed according to the intention to treat principle. Chi-square test, Fisher Exact test, Student t-test, and Mann-Whitney U test, were used for comparing data. The statistician was not aware of the groups of the study. P-value $\leq 0.05$ was considered statistically significant.

\section{Results}

One hundred forty-five women were assessed for eligibility, and finally 116 women finished the study (33 women in the titrated group, 33 women in the oral group and 50 women in the EASI group) (Fig. 1).

The three groups did not have significant difference according to maternal age, gestational age at the time of admission; gravidity, parity, and primary Bishop Score (Table 1). The mean Bishop was $2.3 \pm 1.2$. There was no significant difference between the three groups for the main outcome, which was vaginal delivery during the first 24 hours. There was no significant difference between the three groups according to uterine hypertonicity, uterine hyperstimulation, meconium passage, non-reassuring FHR, neonatal Apgar score in minutes one and five, and mean duration of beginning of intervention up to delivery (Table 2), however, uterine tachysystole and NICU admission were higher in the titrated group. ( $p=0.002$ and $p=0.037$ respectively) (Table

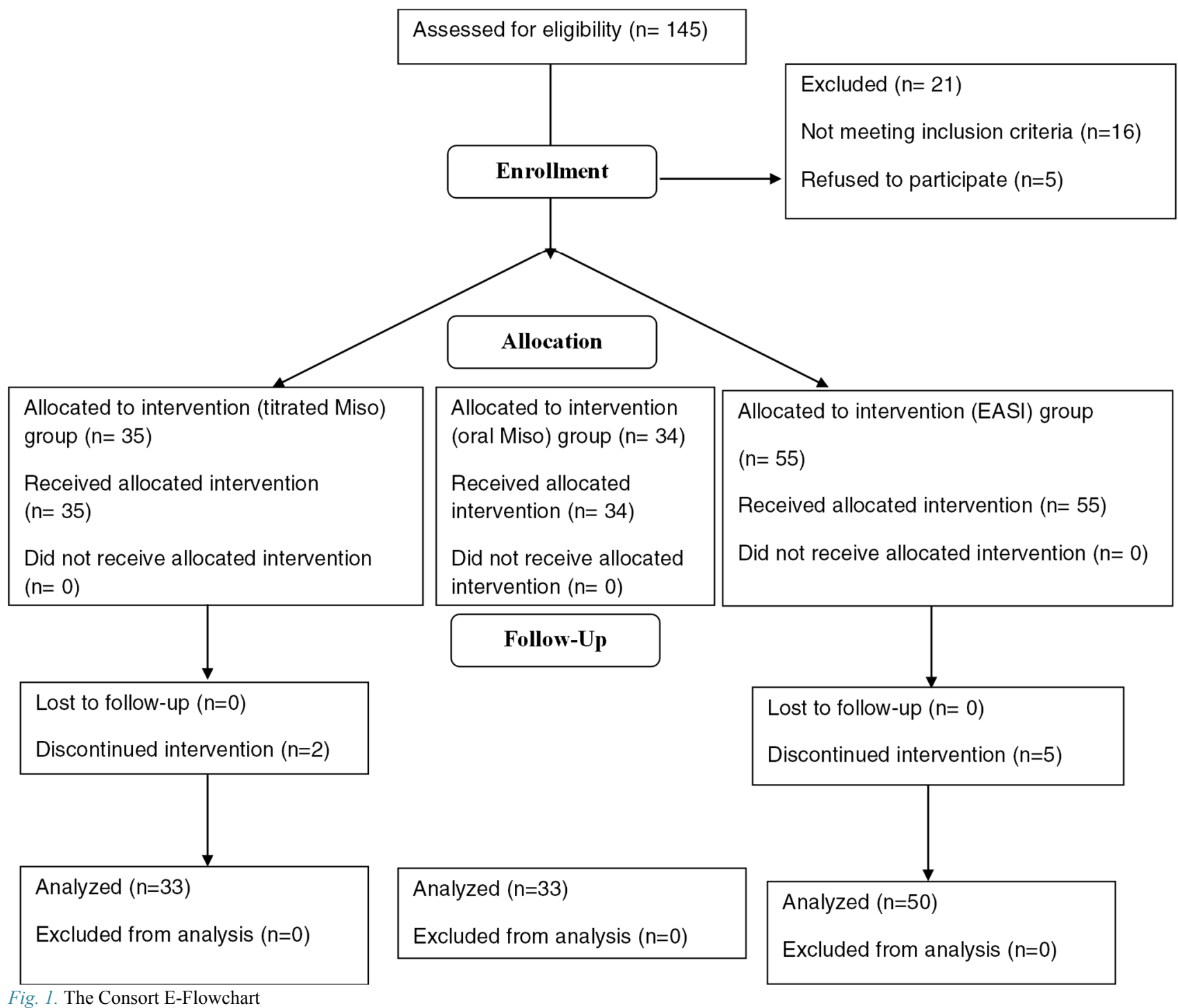


M. Kashanian, et al.

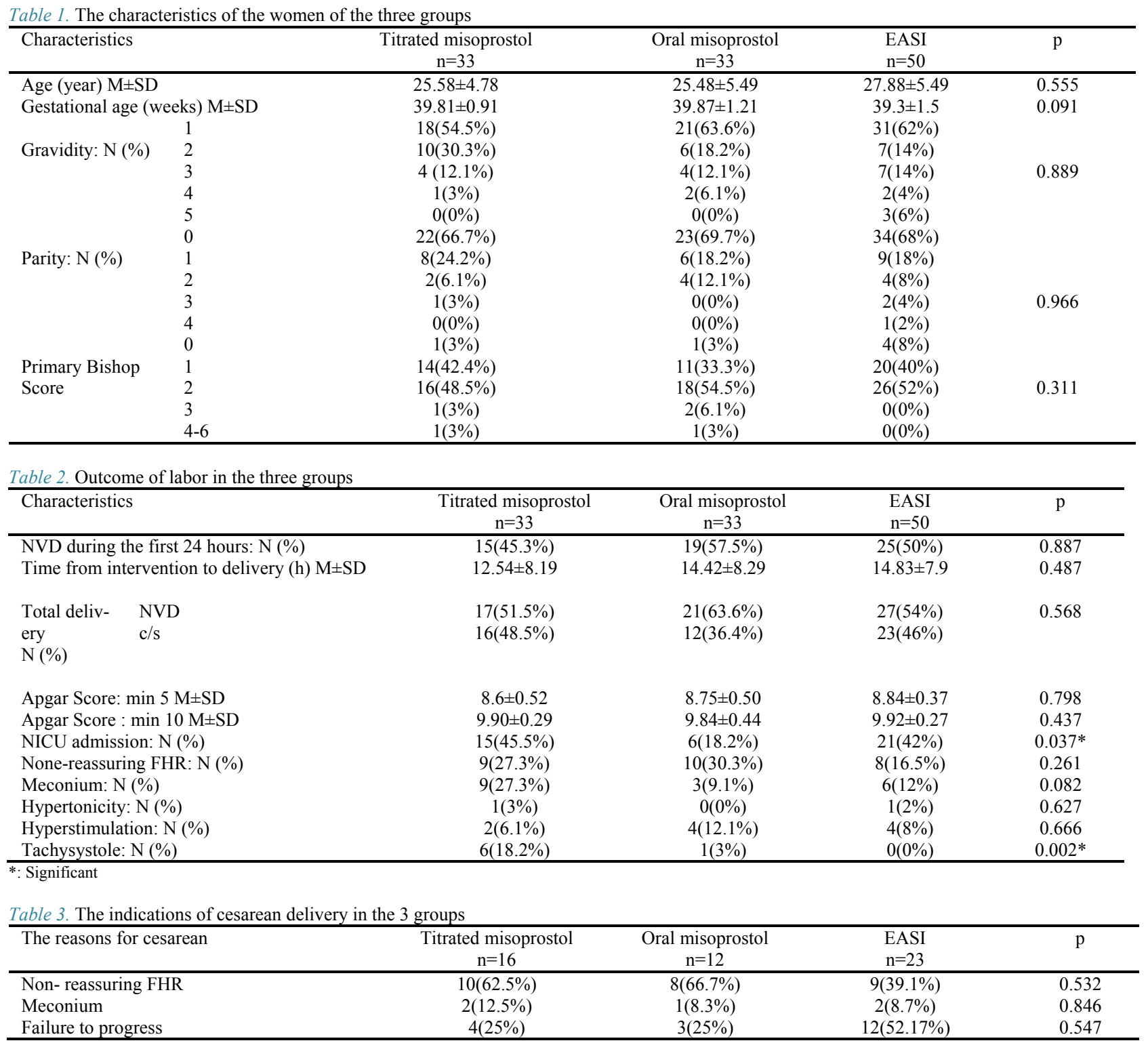

2). The number of cesarean deliveries due to failure to progress was higher in the EASI group. However, EASI group showed the least none-reassuring FHR between the three groups. Meconium passage was more in the titrated misoprostol group, but the difference was not significant. Occurrences of NICU admission were more in the group with titrated solution of misoprostol, because meconium passage was more and unfortunately in our hospital, this is the only reason for admitting the neonate in the NICU.

The causes for cesarean section in the three groups are shown in Table 3. In the titrated group, 29 women had appropriate contractions after 4 hours $(80 \mu \mathrm{g}$ misoprostol), and the remaining four women had appropriate contractions after 6 hours $(160 \mu \mathrm{g})$ who all delivered vaginally.

In the oral misoprostol group, 31 women had appropriate contractions with four doses $(200 \mu \mathrm{g})$ of misoprostol and in two cases received six doses $(250 \mu \mathrm{g})$ for obtaining appropriate contractions, and these two cases had vaginal delivery. The minimum time from intervention to delivery was
3 hours in the titrated group, and maximum duration of intervention was 31 hours. These time periods for the other 2 groups were 4 hours and 41 hours for the oral misoprostol group and 5 hours and 35 hours for EASI group respectively, which did not show a significant difference.

\section{Discussion}

In the present study, the number of vaginal deliveries during the first 24 hours were not different between the three groups. In addition, number of cesarean deliveries, mean interval between the beginning of intervention up to delivery, and neonatal Apgar scores, were not different between groups. However, uterine tachysystole and neonatal NICU admissions were higher in the titrated misoprostol group. Meconium passage was more in the titrated solution group, but the difference was not significant. Fetal distress, uterine hyperstimulation, and uterine hypertonicity were not different between the three groups. Cesarean section due to failure to progress was more in the EASI group. Cesarean delivery due to non-reassuring FHR was less in this group; 
however, the difference was not significant. These results are comparable with other studies.

The main limitation of this study was that it was not a randomized trial. It can cause a major selection bias. The sample size was small, especially in groups with misoprostol, and it lowers the power of the study.

Various methods of labor induction have been used throughout the world and have been compared for safety, efficiency, cost-effectiveness and patient friendliness. Several studies have been performed on different methods of cervical ripening and induction of labor in the cases of unripe cervix with semi-comparable results.

PGS was used for labor induction from 1960s (12), and several studies have been performed for their efficacy and safety. Using titrated solution of misoprostol has been suggested as an alternative to oxytocin in the hospitals without enough facilities for electronic infusion and careful monitoring of oxytocin; because the probability of uterine hyperstimulation with oxytocin is more common, (11). Oral misoprostol solution has been proposed as a safe and effective method in comparison with standard methods of induction of labor with oxytocin $(8,9)$.

Oral misoprostol is preferable to vaginal misoprostol especially in the cases in which the risk of ascending infection is higher while using the vaginal route $(4,10)$.

A comparison between the vaginal and sublingual usage of misoprostol showed similar efficacy, but meconium liquor was higher in the sublingual route (6). Also, vaginal and oral misoprostol, were compared for induction of labor. However, the best routes and dosages of misoprostol are still debatable and deserve more research (7).

Many obstetricians prefer to use dinoprostone (PGE2), instead of misoprostol, which has the legal license for induction of labor (10). In comparison between misoprostol and dinoprostone for induction of labor $(13,35)$, misoprostol led to more vaginal deliveries during the first 24 hours. However, uterine tachysystole and hyperstimulation were more in the misoprostol group. Using single doses of $50 \mu \mathrm{g}$ vaginal misoprostol was more cost-effective and efficient than vaginal insert of dinoprostone $10 \mathrm{mg}$ (15). In addition, oral titrated solution of misoprostol has been reported as effective as vaginal dinoprostone for labor induction in term pregnancies with less adverse effects (14). Comparison between $25 \mu \mathrm{g}$ and $50 \mu \mathrm{g}$ vaginal misoprostol, have proved more efficacy for higher dosages, but higher rates of uterine tachysystole and hyperstimulation, cesarean delivery due to non-reassuring FHR, NICU admission and meconium passages were reported (36). This study supported that $25 \mu \mathrm{g}$ dosages are generally safer options. Different responses to various routes and dosages of PGS might be attributable to different ethnical backgrounds (37).

Mechanical methods have been compared with PGS in different studies, and acceptable and similar results have been reported for two methods $(5,16,38-39)$. Even in the cases of ruptured membrane for more than 18 hours, Foley catheter has been used for induction of labor and was effective and safe in comparison with misoprostol (38). Comparison between mechanical methods and misoprostol has shown more cases of uterine hyperstimulation in using misoprostol. However the rate of vaginal deliveries during the first 24 hours has been the same, although, mechanical methods had lower rates of cesarean deliveries in comparison with oxytocin (3).

A comparison between Foley catheter and vaginal dinoprostone for induction of labor did not show significant difference according to cost-effectiveness because Foley catheter group had a longer duration of labor and were in the labor ward for a longer duration (16); however, efficacy on delivery rate was the same for the two groups.

A meta-analysis (39) which compared the effectiveness of Foley catheter and misoprostol, did not find a significant difference for the cesarean section rate between the two groups, while the rate of hyperstimulation and FHR changes and instrumental vaginal delivery were less reported in the Foley catheter group (39). This study has supported Foley catheter as a safe and effective method for cervical ripening with more benefits. The other study has also proposed comparable results (40).

The combination of these different methods has also been compared $(5,41,42)$. Using combination of misoprostol and Foley catheter for cervical ripening in comparison with misoprostol alone (41), showed shorter duration intervals to delivery and less uterine tachysystole in the combination group, however, the rate of chorioamnionitis was higher, and the rate of cesarean did not differ. This study is in accordance with the other study concerning efficacy and safety (42).

The main limitation of the present study was to assign the women based on the choice of an obstetrician that can introduce large bias to the study, however, in the end, there were no significant differences between the groups for confounding factors.

Regarding the above-mentioned studies and the present study, all three methods are appropriate methods for induction of labor in the cases of unfavorable cervix; and choosing each method depends on the expertise of labor staff, accessibility to the medications, cost, and taking care for monitoring the patients and adverse effects.

\section{Conflict of Interests}

The authors declare that they have no competing interests.

\section{References}

1. Kelly AJ, Alfirevic Z, Ghosh A. Outpatient versus inpatient induction of labour for improving birth outcomes. Cochrane Database Syst Rev. 2013 Nov 12;11:CD007372.

2. Budden A, Chen LJ, Henry A. High-dose versus low-dose oxytocin infusion regimens for induction of labour at term. Cochrane Database Syst Rev. 2014 Oct 9;10:CD009701.

3. Jozwiak M, Bloemenkamp KW, Kelly AJ, Mol BW, Irion O, Boulvain M. Mechanical methods for induction of labour. Cochrane Database Syst Rev. 2012 Mar 14;3:CD001233.

4. Hofmeyr GJ, Gülmezoglu AM, Pileggi C. Vaginal misoprostol for cervical ripening and induction of labour. Cochrane Database Syst Rev. 2010 Oct 6;(10):CD000941.

5. Kashanian M, Akbarian AR, Fekrat M. Cervical ripening and induction of labor with intra-vaginal misoprostol and Foley catheter cervical traction. Inter J of Obstet Gynecol. 2006 Jan;92(1):79-80.

6. Jahromi BN, Poorgholam F, Yousefi G, Salarian L. Sublingual versus Vaginal Misoprostol for the Induction of Labor at Term: A Randomized, Triple-Blind, Placebo-Controlled Clinical Trial. Iran J Med Sci. 2016 Mar;41(2):79-85 
7. Rezaie M, Farhadifar F, Sadegh SM, Nayebi M. Comparison of Vaginal and Oral Doses of Misoprostol for Labour Induction in Post-Term Pregnancies. J Clin Diagn Res. 2016 Mar;10(3):QC08-11.

8. Mbaluka CM, Kamau K, Karanja JG, Mugo N. Effectiveness and safety of 2-hourly $20 \mathrm{Mcg}$ oral misoprostol solution compared to standard intravenous oxytocin in labour induction due to pre-labour rupture of membranes at term: a randomised clinical trial at kenyatta national hospital. East Afr Med J. 2014 Sep; 91(9):303-10.

9. Bricker L, Peden H, Tomlinson AJ, Al-Hussaini TK, Idama T, Candelier C, et al. Titrated low-dose vaginal and/or oral misoprostol to induce labour for prelabour membrane rupture: a randomized trial. BJOG. 2008 Nov;115(12):1503-11.

10. Alfirevic Z, Aflaifel N, Weeks A. Oral misoprostol for induction of labour. Cochrane Database Syst Rev. 2014 Jun 13;6:CD001338.

11. Vogel JP, West HM, Dowswell T. Titrated oral misoprostol for augmenting labour to improve maternal and neonatal outcomes. Cochrane Database Syst Rev. 2013 Sep 23;9:CD010648.

12. Thomas J, Fairclough A, Kavanagh J, Kelly AJ. Vaginal prostaglandin (PGE2 and PGF2a) for induction of labour at term. Cochrane Database Syst Rev. 2014 Jun 19;6:CD003101.

13. Rouzi AA, Alsibiani S, Mansouri N, Alsinani N, Darhouse K. Randomized clinical trial between hourly titrated oral misoprostol and vaginal dinoprostone for induction of labor. Am J Obstet Gynecol. 2014 Jan;210(1):56.e1-6.

14. Wang X, Yang A, Ma Q, Li X, Qin L, He T. Comparative study of titrated oral misoprostol solution and vaginal dinoprostone for labor induction at term pregnancy. Arch Gynecol Obstet. 2016 Jan 8.

15. Nadia Bennett K, Park H, Cioffi J, Calixte R, Vintzileos A. A comparison of obstetrical outcomes and costs between misoprostol and dinoprostone for induction of labor. J Matern Fetal Neonatal Med. 2016 Feb 26:1-5. [Epub ahead of print]

16. van Baaren GJ, Jozwiak M, Opmeer BC, Oude Rengerink K, Benthem M, Dijksterhuis MG, et al. Cost-effectiveness of induction of labour at term with a Foley catheter compared to vaginal prostaglandin $\mathrm{E}_{2}$ gel (PROBAAT trial). BJOG. 2013 Jul;120(8):987-95.

17. Hapangama D, Neilson JP. Mifepristone for induction of labour. Cochrane Database Syst Rev. 2009 Jul 8;(3):CD002865.

18. Kelly AJ, Munson C, Minden L. Nitric oxide donors for cervical ripening and induction of labour. Cochrane Database Syst Rev. 2011 Jun 15;(6):CD006901.

19. Kashanian M, Hasankhani S, Sheikhansari N, Bahasadri S, Homam $\mathrm{H}$. The effects of sequential use of oxytocin and sublingual nitroglycerin in the cases of retained placenta. J Matern Fetal Neonatal Med. 2015 Dec 23:1-6. [Epub ahead of print]

20. Kavanagh J, Kelly AJ, Thomas J. Corticosteroids for cervical ripening and induction of labour. Cochrane Database Syst Rev. 2006 Apr 19;(2):CD003100.

21. Kashanian M, Fekrat M, Naghghash S, Sheikh Ansari N. Evaluation of the effect of extra-amniotic normal saline infusion (EASI) alone or in combination with dexamethasone for the induction of labor. J Obstet Gynaecol Res. 2008 Feb; 34(1):47-50.

22. Kashanian M, Dadkhah F, Mokhtari F. Effect of intramuscular administration of dexamethasone on the duration of labor. Int J Gynaecol Obstet. 2008 Sep;102(3):259-62

23. Kashanian M, Fekrat M, Zarrin Z, Sheikh Ansari N. A comparison between the effect of oxytocin only and oxytocin plus propranolol on the labor (a double blind randomized trial). J Obstet Gynaecol Res. 2008 Jun; 34(3):354-8.

24. Thomas J, Kelly AJ, Kavanagh J. Oestrogens alone or with amniotomy for cervical ripening or induction of labour. Cochrane Database Syst Rev. 2001;(4):CD003393.

25. Kavanagh J, Kelly AJ, Thomas J. Hyaluronidase for cervical ripening and induction of labour. Cochrane Database Syst Rev. 2006 Apr 19;(2):CD003097.

26. Kelly AJ, Kavanagh J, Thomas J. Relaxin for cervical ripening and induction of labour. Cochrane Database Syst Rev. 2001;(2):CD003103.

27. Kashanian M, Akbarian AR, Baradaran H. Extra-amniotic saline infusion vs. cervical traction with Foley catheter for second-trimester pregnancy termination. Int J Gynaecol Obstet. 2006 Feb;92(2):159- 60.

28. Kashanian M, Nazemi M, Malakzadegan A. Comparison of 30-mL and $80-\mathrm{mL}$ Foley catheter balloons and oxytocin for preinduction cervical ripening. Int J Gynaecol Obstet. 2009 May;105(2):174-5

29. Kashanian M, Akbarian AR, Baradaran H, Samiee MM: Effect of Membrane Sweeping at Term Pregnancy on Duration of Pregnancy and Labor Induction: A Randomized Trial. Gynecol Obstet Invest. 2006 Mar 3;62(1):41-44

30. Kavanagh J, Kelly AJ, Thomas J. Breast stimulation for cervical ripening and induction of labour. Cochrane Database Syst Rev. $2005 \mathrm{Jul}$ $20 ;$; (3):CD003392.

31. Kavanagh J, Kelly AJ, Thomas J. Sexual intercourse for cervical ripening and induction of labour. Cochrane Database Syst Rev. 2001;(2):CD003093.

32. Kafaei Atrian M, Sadat Z, Rasolzadeh Bidgoly M, Abbaszadeh F, Asghari Jafarabadi M. The association of sexual intercourse during pregnancy with labor onset. Iran Red Crescent Med J. 2014 Dec 26; 17(1):e16465.

33. Kelly AJ, Kavanagh J, Thomas J. Castor oil, bath and/or enema for cervical priming and induction of labour. Cochrane Database Syst Rev. 2013 Jul 24;7:CD003099.

34. Kashanian M, Shahali S. Effects of acupressure at the Sanyinjiao point (SP6) on the process of active phase of labor in nulliparas women. J Matern Fetal Neonatal Med. 2009 Sep 15:1-4.

35. Crane JM, Butler B, Young DC, Hannah ME. Misoprostol compared with prostaglandin $\mathrm{E} 2$ for labour induction in women at term with intact membranes and unfavourable cervix: a systematic review. BJOG. 2006 Dec;113(12):1366-76.

36. McMaster K, Sanchez-Ramos L, Kaunitz AM. Balancing the efficacy and safety of misoprostol: a meta-analysis comparing 25 versus $50 \mathrm{mi}-$ crograms of intravaginal misoprostol for the induction of labour. BJOG. 2015 Mar; 122(4):468-76.

37. Stephenson ML, Hawkins JS, Pevzner L, Powers BL, Wing DA. Racial/Ethnic Differences in Labor Outcomes with Prostaglandin Vaginal Inserts. J Racial Ethn Health Disparities. 2015 Jun;2(2):149-57.

38. Kruit H, Tihtonen K, Raudaskoski T, Ulander VM, Aitokallio-Tallberg A, Heikinheimo O, et al. Foley Catheter or Oral Misoprostol for Induction of Labor in Women with Term Premature Rupture of Membranes: A Randomized Multicenter Trial. Am J Perinatol. 2016 Mar 31. [Epub ahead of print]

39. Jozwiak M, ten Eikelder M, Oude Rengerink K, de Groot C, Feitsma $\mathrm{H}$, Spaanderman M, et al. PROBAAT Study Group. Foley catheter versus vaginal misoprostol: randomized controlled trial (PROBAAT-M study) and systematic review and meta-analysis of literature. Am J Perinatol. $2014 \mathrm{Feb} ; 31(2): 145-56$.

40. Jozwiak M, Oude Rengerink K, Ten Eikelder ML, van Pampus MG, Dijksterhuis MG, de Graaf IM, et al. Foley catheter or prostaglandin E2 inserts for induction of labour at term: an open-label randomized controlled trial (PROBAAT-P trial) and systematic review of literature. Eur J Obstet Gynecol Reprod Biol. 2013 Sep;170(1):137-45.

41. Chen W, Xue J, Gaudet L, Walker M, Wen SW. Meta-analysis of Foley catheter plus misoprostol versus misoprostol alone for cervical ripening. Int J Gynaecol Obstet. 2015 Jun;129(3):193-8.

42. Carbone JF, Tuuli MG, Fogertey PJ, Roehl KA, Macones GA. Combination of Foley bulb and vaginal misoprostol compared with vaginal misoprostol alone for cervical ripening and labor induction: a randomized controlled trial. Obstet Gynecol. 2013 Feb;121(2 Pt 1):247-52. 